\title{
MANAGERIAL LEVEL, MANAGERIAL MOTIVATION AND SENSE OF COHERENCE
}

\author{
MG COETZEE \\ AM VIVIERS \\ vivieam@unisa.ac.za \\ DELÉNE VISSER \\ Department of Industrial and Organisational Psychology \\ University of South Africa
}

\begin{abstract}
The first objective of the study was to assess whether the dimensions of Antonovsky's Sense of Coherence (SOC) scale correlated positively with those of the Managerial Motivation scale (MMQ). The second objective was to establish whether managers and supervisors differed with regard to sense of coherence and managerial motivation. The respondents were 124 employees of the Agricultural Research Council. None of the sense of coherence scales correlated with Attitude towards authority figures (MMQ). Also, Meaningfulness (SOC) and Willingness to conduct administrative functions (MMQ) did not correlate. However, the remainder of the correlations supported the hypothesis, indicating a strong positive relationship between managerial motivation and sense of coherence. Statistically significant differences between managers and supervisors were obtained for only two variables, namely Meaningfulness (SOC) and Power motive (MMQ).
\end{abstract}

Key words

Sense of coherence, managerial motivation, meaningfulness, proper motive, managing

According to the Global Competitiveness Report (1999) issued by the World Economic Forum, South Africa ranks 47th on the list of 59 countries that were evaluated during 1999 in terms of growth competitiveness. Because management was one of the eight factors or attributes taken into account during the compilation of the report, one may assume that management is seen as a very important factor that influences the competitiveness of a country, and also a company. Although the Global Competitiveness Report (2000) ranked South Africa 33rd on a list of 59 countries in 2000, and management per se was not regarded as the poorest attribute of South Africa's competitiveness, the ranking for management indicated that it would be difficult for South Africa to compete in the global market, especially with first-world markets. These findings implied that South Africa's management performance could be significantly enhanced.

A factor to consider is that the composition of the management echelon in companies in South Africa is currently changing dramatically as a result of the provisions and implementation of the Employment Equity Act of 1998. The Breakwater Monitor Report (2000) stated that Africans in managerial positions have increased from 6\% in 1998 to $7 \%$ in 1999 , and to $10 \%$ in 2000 . The figure for both coloureds and Indians/Asians were $4 \%$ (1998), 4\% (1999) and 5\% (2000). In the same period the representation of whites in managerial positions declined from $86 \%$ (1998) to $85 \%$ (1999), and then to $80 \%$ (2000). This scenario and the promulgation of the Employment Equity Act have as consequence the rapid entering of new managers from the designated groups in particular into the management echelon.

The drive to appoint employment equity candidates in managerial positions in organisations brought about competitiveness, because white managers realised the need to perform well, whereas black managers realised that they needed to be worthy candidates for their respective positions. Appointment to a position and promotion in particular takes performance into consideration and this performance excellence is driven by individuals' motivation to occupy managerial positions. The race against employability and promotion consequently requires a strong degree of motivation, but it will also cause stress for motivated managers. Those who are strongly motivated are expected to have coping skills to help them to process effectively the challenges and demands of a changing and competitive South Africa.

\section{Managerial motivation}

Strümpfer (1990) mentioned that the majority of adults spend the largest portion of their waking hours in the workplace. It therefore becomes a dominant source of external and internal stimulation to be comprehended, managed and made meaningful. Strümpfer (2005) highlighted the theory of Deci (1975) of intrinsic motivation. This theory explains the inherent human tendency to be self-motivated, to seek out challenges and to extend one's capacities by mastering new skills and to apply them responsibly so as to act competently in dealing with the environment. Managerial motivation may be seen as a component of such intrinsic motivation, because managers who are motivated strive towards furthering their careers and aspire to be promoted. It would be logical to expect that senior managers show a higher degree of managerial motivation than lower level managers or supervisors, because their motivational drive, amongst a variety of possible factors, took them to more senior positions. In analysing the work done by Kohn and Schooler, (1982, 1983), and Kohn and Slomczynski (1990), Strümpfer (1995) came to the conclusion that the process of occupational self-directed development over time leads to more responsible jobs, which in turn, allow greater latitude for selfdirection on the job and thus for a virtuous cycle of reciprocal influences to continue.

Spangenberg (1990) mentioned that overall managerial motivation appears to correlate significantly with certain criteria for managerial effectiveness, namely performance appraisal, job grade, number of subordinates and managerial level. It also appears that overall managerial motivation is significantly related to overall managerial potential. Spangenberg (1990) also pointed out that a significant positive relationship exists between managerial motivation and managerial satisfaction, and satisfaction with managerial work and advancement. Enhanced managerial motivation amongst managers would probably lead to improved managerial competence in a company and ultimately to an improvement in the performance of that company. Enhanced performance may eventually lead to a better global competitiveness rating.

The concept of managerial motivation is important in identifying future managers, but unfortunately the concept as such has received little attention in the literature so far. According to Engelbrecht (1991), it was mainly McClelland (1987) and Miner $(1965,1978)$ who attempted to conceptualise 
the concept of managerial motivation and measure it empirically. McClelland (1987) defined managerial motivation in terms of three motives, namely the need for affiliation, the need for performance and the need for power. The managerially motivated person will therefore probably have a low affiliation motive, a moderate performance motive and a high power motive. In contrast, Miner (1965) proposed that managerial motivation comprises six motives, namely a positive attitude towards authority figures, competitiveness, assertiveness, power motive, the desire for a distinctive group role, and a willingness to do administrative work. A managerially motivated person would probably have a high tendency towards all of these.

Engelbrecht and De Jager (1991) noted that the multiplechoice Miner Sentence Completion Scale (MSCS), developed by Miner (1965) and used to measure managerial motivation, was adapted after it had been criticised widely. Upon determining the internal consistency and factor structure of the adapted MSCS, it was found that the reliability was unsatisfactory and that the factor structure was too complex to allow for clear interpretation regarding validity. These deficiencies regarding the psychometric attributes of the MSCS led Engelbrecht and De Jager (1991) to conclude that the MSCS cannot test the role-motivation theory adequately. In the absence of another measuring instrument for managerial motivation, as operationalised by the role-motivation theory of Miner (1965), Engelbrecht (1989) embarked upon the development of a new instrument to measure managerial motivation. Many years earlier, Fineman (1977) suggested that this option should be investigated.

\section{Stress and sense of coherence}

Stress is omnipresent in the lives of all human beings (Antonovsky, 1984a) and the work lives of individuals are no exception. Dana and Griffin (1999) pointed out that stress per se is recognised as an important component and major problem of everyday life, threatening individual, organisational and societal health. They referred to a study reported by Boyd (1997) that $88 \%$ of respondents reported physical and/or psychological reactions to work pressure. Spangenberg and Orpen-Lyall (2000) found that many South African managers experience high stress levels in the work situation.

Semmer (2003) mentioned that people who have the tendency to cope by dealing actively with a problem tend to be better off than others. Sense of coherence is an approach or model that focuses on successful coping with omnipresent stressors in human existence (Strümpfer, 1990). Similarly, Wissing and Van Eeden, (1997) mentioned that sense of coherence appears to be a good indicator of general psychological well-being. It is clear that individuals who effectively cope with stressors have certain skills or orientations to help them cope on a daily basis.

Strümpfer (1990) argued that in an organisational environment, persons with an orientation towards a strong sense of coherence would experience productive performance, recognition, reward and promotion. Such persons would (p 270):

- make cognitive sense of the workplace, perceiving its stimulation as clear, ordered, structured, consistent and predictable information

- perceive their work as consisting of experiences that are bearable, with which they can cope, and as challenges that they can meet by availing themselves of personal resources or resources under the control of legitimate others

- make emotional and motivational sense of work demands, see them as welcome challenges, worthy of engaging in and investing their energies in

These three aspects refer to the three components of comprehensibility, manageability and meaningfulness of the sense of coherence scale as Antonovsky (1984a, 1993) formulated it. Antonovsky (1984a) explained the motivational element of a sense of coherence and pointed out that the component of meaningfulness refers to the aspect that "things make sense" (p 7). He provided an example: academic life may be seen to have clearly perceived rules and order, and that a person can see him-/herself as managing competently, but that the person may just not care enough about the job to invest any kind of energy in involvement. Antonovsky (1991) elaborated on the motivational element (why should I do something?) of a sense of coherence and stated that (p 95) "When others decide everything for us... we are reduced to being objects. A world thus experienced as being indifferent to what we do comes to be seen as a world devoid of meaning". Antonovsky (1984b) argued that, as far as work is concerned, intrinsic motivation does not necessarily act as the driving motive. People may find little joy in their work, but if they feel that the work has a meaning because it is how they support their families and keep it functioning smoothly and happily, they still have a strong sense of coherence.

Strümpfer (1992) stressed that a sense of coherence is directly related to different aspects of successful living, and referred to effective performance of work and career effectiveness. He quoted Antonovsky (1987, p 182) who indicated that when a task is particularly ambiguous and complex, a strong sense of coherence will be a contributing factor for the motivated person to see the task as a challenge. Semmer (2003) summarised a number of studies and indicated that a sense of coherence shows relationships with a number of indicators of well-being and health, as well as with working conditions. Although Strümpfer (1992) referred to a number of studies in South Africa done on sense of coherence and work-related variables, no specific investigation between sense of coherence and managerial motivation have been cited. Viviers (1996) found relationships between sense of coherence and work orientation concepts such as job involvement and organisational commitment, and indicated that work orientation also includes the concept of motivation. He found that sense of coherence correlated significantly with other work orientation concepts and that optimalisation can be considered a central factor. This implies an element of motivation and occupational self-directedness. Strümpfer (2003) did a meta-analysis of sense of coherence and job satisfaction and came to the conclusion that higher job satisfaction would be a result if an employee makes emotional and motivational sense of work demands. Meaning-providing variables may therefore, assist in warding off burnout (a possible consequence of prolonged stress).

From the above it is clear that managerial motivation plays a role in the advancement of managers. Managers also experience stress due to their motivation to reach senior positions. For managers to cope effectively, they need to have certain coping skills or life orientations to assist them with daily stressors and to reach optimisation as persons and managers. One of these orientations may be a strong sense of coherence - the ability to view life and work stressors as comprehensible, manageable and meaningful. The goal of the present study was to investigate whether managers with a strong sense of coherence also display a strong drive toward managerial motivation.

The aim of the present study was therefore two-fold, namely

- to establish whether there were statistically significant positive relationships between the sub-dimensions of sense of coherence and managerial motivation, and

- to establish whether there were statistically significant differences between managers and supervisors on the subdimensions of the sense of coherence and managerial motivation constructs.

The study was conducted within the context of a statutory organisation that had its structure arranged in a hierarchical manner, reflecting a bureaucratic system. 


\section{RESEARCH DESIGN}

\section{Research approach}

An exploratory non-experimental field study was conducted to study the relationships among continuous variables by means of quantitative methodology.

\section{Participants}

The two populations that were studied comprised of 117 managers and 225 supervisors. They were employees of an agricultural research statutory organisation that consisted of a central office and 13 different institutes. At each of the institutes, research on a particular aspect or discipline related to agriculture was being conducted. The jobs at the institutes were arranged in a hierarchical manner, reflecting a bureaucratic system. Each institute was headed by a director who was assisted by a number of deputy directors. These in turn had a number of assistant directors reporting to them.

The population of managers consisted of all the deputy directors and assistant directors at job levels 7 to 9 (according to an internally developed job grading system). They were regarded as middle level managers with the typical duties and responsibilities that accompany such positions. A sample of 56 managers $(47,9 \%$ of the population) participated in the study, but five managers submitted incomplete questionnaires that had to be discarded.

Of the remaining 51 managers, 42 were male and nine were female. Although the ages of the managers varied from 27 to 63 years, the majority were in the age group of 40 to 59 years, with a mean age of 47,1 years. Most of the respondents were Afrikaans-speaking $(\mathrm{N}=43)$, whereas seven were Englishspeaking and one respondent was Pedi-speaking. The majority of the managers were working as researchers in the agricultural discipline $(\mathrm{N}=27)$, but 16 managers indicated that their jobs should be classified as managerial.

The population of supervisors consisted of all the supervisors at job levels 5 and 6 . They were responsible for the typical duties that accompany supervisory positions. A sample of 73 supervisors $(32,4 \%$ of the population) participated in the study. Thirty of the supervisors were male, 33 were female and 10 respondents did not indicate their gender grouping. The mean age of the supervisors was 38,5 years and their ages ranged from 25 to 61 years. Twenty-nine supervisors were in the age group of 30 to 39 years. The majority of respondents were Afrikaansspeaking $(\mathrm{N}=47), 16$ were English-speaking and 10 respondents did not indicate their language grouping. The majority of the supervisors were involved in research-related work in the agricultural discipline (50).

The combined sample consisted of 41,1 percent managers and 58,9 percent supervisors. Of these, 62 percent were male and 38 percent female. The majority of respondents were in the age group of 30 to 39 years and the overwhelming majority was Afrikaans-speaking. Sixty four percent of the respondents indicated that their work experience lay in the field of research, whereas the remaining $36 \%$ mentioned that their experience were in the fields of management, human resources or finance.

\section{Measuring instruments}

The independent variable, sense of coherence, was measured by means of the Orientation to Life questionnaire, developed by Antonovsky (1993). The dependent variable, managerial motivation, was measured using the Managerial Motivation Questionnaire (MMQ) developed by Engelbrecht (1989, 1991).

\section{Managerial Motivation Questionnaire (MMQ)}

Using Miner's (1978) six motives as the dimensions for a new questionnaire, Engelbrecht (1989) developed the Managerial Motivation Questionnaire (MMQ). The preliminary MMQ was systematically shortened and refined using item analysis and factor analysis, resulting in the final 98-item MMQ. Special care was taken to address the problem of social desirability. Initially an internal consistency reliability coefficient of 0,72 for the total scale was found in Engelbrecht's (1989) study using 103 managers. Subsequently, internal consistencies were computed for two more samples, with coefficient alpha values of $0,90(\mathrm{~N}=360)$ and $0,91(\mathrm{~N}$ $=535$ ), respectively (Engelbrecht, 1991). The alphas for the subscales ranged from 0,71 to 0,83 with an mean value of $0,80(\mathrm{~N}=535)$.

According to Spangenberg (1990) considerable evidence of construct validity was found during the construction of the instrument. By means of factor analysis the MMQ was constructed so that all subscale items were relatively pure measures of the isolated factors. The factor analytical results produced six factors that could be linked to the postulated six dimensions of managerial motivation.

In the MMQ there are 10 Attitude towards authority figures items, 23 Competitiveness items, 19 Assertiveness items, 22 Power motive items, 12 Desire for a distinctive group role items and 12 Willingness to conduct administrative functions items. Both positively and negatively formulated items were included and the 5-point Likert scales were scored so that a high score expressed strong managerial motivation. Total scores on the MMQ provide an estimate of respondents' managerial motivation, whereas totals on the subscales are used to assess respondents' standing on the separate dimensions (Spangenberg, 1990).

Sense of Coherence Scale (SOC scale)

The SOC scale (Orientation to Life questionnaire) was developed by Antonovsky (1993) to measure overall sense of coherence, as well as to measure the following three dimensions separately: comprehensibility (seeing the world as structured and predictable); manageability (believing that the individual has adequate personal and social resources to meet environmental demands and circumstances); and meaningfulness (feeling that it is worthwhile to try to cope actively within stressful circumstances). Sense of coherence refers to a global orientation to one's inner and outer environments.

The SOC scale is a 29-item semantic differential questionnaire and its design was guided by Guttman's facet theory. Respondents are asked to select a response on a seven-point semantic differential scale with two anchoring phrases. There are 11 comprehensibility items, 10 manageability items and eight meaningfulness items. Thirteen of the items are formulated negatively and their scoring has to be reversed so that a high score expresses a strong sense of coherence.

Antonovsky (1993) summarised the Cronbach alpha measures of internal consistency that were reported for 26 studies that used the SOC-29. In eight published studies the mean alphas ranged between 0,86 and 0,95. Consistently high internal consistencies were found in a variety of populations, languages and cultures.

In a study in which the psychological properties of the SOC scale were examined, Frenz, Carey and Jorgenson (1993) found an alpha coefficient of $0,93(\mathrm{~N}=370)$ for the total scale. They also reported a high test-retest reliability $(\mathrm{r}=0,92, \mathrm{p}<0,0001)$ for a one-week retest interval for a sample of 171 respondents. In South Africa, Strümpfer and Wissing (1998) found that the reliabilities of both forms of the SOC scale were generally high. The mean alpha values for 19 studies using the SOC-29 were 0,87 (median 0,89), whereas the mean alphas for the SOC-13 were 0,80 (median 0,79 ).

With regard to the construct validity of the SOC scale, Frenz, Carey and Jorgenson (1993) found that the three components of the SOC scale suggested by Antonovsky (1979) did not emerge as three separate factors. Their factor analytic results suggested that the scale has one core factor and therefore appears to be a onedimensional instrument measuring sense of coherence.

Further validity evidence of the SOC scale yielded mixed results. 
Evidence that supported the construct validity of the SOC scale included the finding of an inverse relationship between sense of coherence and perceived stress (Frenz et al., 1993). This supported Antonovsky's view that individuals with a high sense of coherence are less likely to appraise stimuli as stressors than those with a weak sense of coherence. In the same vein, Flannery, Perry, Penk and Flannery (1994) found significant negative correlations between the sense of coherence dimensions (comprehensibility, manageability and meaningfulness) and measures of life stress and psychological distress. As expected, sense of coherence scores were found to be higher in non-patients than in patients (Frenz et al., 1993), thereby providing further empirical support for the construct validity of Antonovsky's SOC scale.

In South Africa, Strümpfer and Wissing (1998) also demonstrated that the validity of the SOC scale was supported by differences in mean scores between groups (such as psychiatric patients versus non-psychiatric patients and depressed versus non-depressed respondents) that could theoretically be expected to differ.

Evidence not in support of the validity of the sense of coherence measure related to the significant positive correlation between sense of coherence and social desirability. This result suggests that sense of coherence items may be somewhat "transparent" and therefore vulnerable to a social desirability response bias (Frenz et al., 1993).

\section{Procedure}

The MMQ and SOC scales were distributed to the total population via e-mail. The e-mail requested recipients to participate and explained the purpose of the research. The procedure was tested on a pilot group before it was mailed to all members of the population. Completed questionnaires were returned by e-mail. A period of three weeks was allowed for responses after which a follow-up request was mailed to all the members. Upon receipt of their responses, the questionnaires were saved in electronic format, each with a unique name. The data was stored in a format that would allow for statistical analyses to be performed.

\section{RESULTS}

The first step of the statistical treatment of the data involved calculating descriptive statistics for the variables. Respondents' scores on the sub-scales were transformed to a scale ranging from zero to 100. The means and standard deviations of the total sample on the MMQ and SOC scales are given in Table 1.

TABLE 1

DESCRIPTIVE STATISTICS FOR SCORES ON THE MMQ AND SOC SCALES FOR THE TOTAL SAMPLE $(\mathrm{N}=124)$

\begin{tabular}{llcc}
\hline & Dimension & M & SD \\
\hline Managerial Motivation & Attitude towards authority figures & 63,91 & 14,39 \\
& Competitiveness & 66,90 & 12,28 \\
& Assertiveness & 63,71 & 13,55 \\
& Power motive & 70,63 & 11,58 \\
& Desire distinctive role & 46,30 & 18,15 \\
& Willingness admin & 69,46 & 16,10 \\
Sense of Coherence & Comprehension & 60,52 & 13,30 \\
& Manageability & 70,71 & 13,68 \\
& Meaningfulness & 77,57 & 13,23 \\
& SOC total & 68,76 & 11,74
\end{tabular}

TABLE 2

SINGLE FACTOR LOADINGS AND CRONBACH ALPHAS FOR THE MMQ SUBSCALES

\begin{tabular}{|c|c|c|c|c|c|c|c|c|c|c|c|}
\hline \multicolumn{2}{|c|}{$\begin{array}{l}\text { Attitude towards } \\
\text { authority figures }\end{array}$} & \multicolumn{2}{|c|}{ Competitiveness } & \multicolumn{2}{|c|}{ Assertiveness } & \multicolumn{2}{|c|}{ Power motive } & \multicolumn{2}{|c|}{$\begin{array}{l}\text { Desire for a distinctive } \\
\text { group role }\end{array}$} & \multicolumn{2}{|c|}{$\begin{array}{l}\text { Willingness to conduct } \\
\text { admin functions }\end{array}$} \\
\hline Item & Loading & Item & Loading & Item & Loading & Item & Loading & Item & Loading & Item & Loading \\
\hline 1 & 0,55 & 2 & 0,72 & 3 & $-0,60$ & 4 & 0,52 & 5 & 0,53 & 6 & 0,40 \\
\hline 7 & 0,43 & 8 & 0,56 & 9 & $-0,37$ & 10 & 0,50 & 11 & 0,41 & 12 & 0,52 \\
\hline 13 & 0,75 & 14 & 0,51 & 15 & 0,48 & 16 & $\underline{0,22}$ & 17 & 0,66 & 18 & 0,35 \\
\hline 19 & 0,60 & 20 & $-0,53$ & 21 & 0,50 & 22 & 0,50 & 23 & 0,83 & 24 & 0,70 \\
\hline 25 & 0,49 & 26 & 0,66 & 27 & 0,42 & 28 & 0,62 & 29 & 0,51 & 30 & 0,64 \\
\hline 31 & 0,45 & 32 & $\underline{0,11}$ & 33 & 0,52 & 34 & 0,37 & 35 & 0,60 & 36 & 0,62 \\
\hline 37 & 0,69 & 38 & 0,69 & 39 & $\underline{0,28}$ & 40 & 0,58 & 41 & 0,61 & 42 & 0,72 \\
\hline 43 & 0,48 & 44 & $\underline{0,23}$ & 45 & $-0,67$ & 46 & 0,49 & 47 & $-0,60$ & 48 & 0,60 \\
\hline 49 & 0,56 & 50 & 0,39 & 51 & 0,33 & 52 & 0,63 & 53 & $-0,68$ & 54 & 0,58 \\
\hline \multirow[t]{14}{*}{55} & 0,73 & 56 & 0,41 & 57 & 0,41 & 58 & 0,45 & 59 & $-0,45$ & 60 & $\underline{0,09}$ \\
\hline & & 61 & 0,44 & 62 & 0,38 & 63 & 0,50 & 64 & $-0,74$ & 65 & 0,65 \\
\hline & & 66 & $\underline{0,27}$ & 67 & 0,62 & 68 & 0,46 & 69 & $-0,44$ & 70 & 0,80 \\
\hline & & 71 & 0,53 & 72 & 0,64 & 73 & $-0,68$ & & & & \\
\hline & & 74 & 0,36 & 75 & 0,53 & 76 & $\underline{0,29}$ & & & & \\
\hline & & 77 & 0,55 & 78 & $-0,36$ & 79 & 0,58 & & & & \\
\hline & & 80 & 0,43 & 81 & 0,55 & 82 & $-0,37$ & & & & \\
\hline & & 83 & 0,45 & 84 & 0,58 & 85 & $-0,59$ & & & & \\
\hline & & 86 & 0,40 & 87 & $-0,45$ & 87 & 0,51 & & & & \\
\hline & & 89 & 0,48 & 90 & $-0,39$ & 91 & $-0,40$ & & & & \\
\hline & & 92 & 0,46 & & & 93 & $-0,53$ & & & & \\
\hline & & 94 & 0,64 & & & 95 & 0,63 & & & & \\
\hline & & 96 & 0,45 & & & 97 & 0,34 & & & & \\
\hline & & 98 & 0,57 & & & & & & & & \\
\hline
\end{tabular}

Alpha $=0,76 \quad$ Alpha $=0,85^{1} \quad$ Alpha $=0,80^{2}$
Factor loadings smaller than 0,30 are printed in bold
1. Item 20 was rescaled to measure in the same direction as the other items
2. Items $15,21,27,33,51,57,62,67,72,75,81$ and 84 were rescaled to measure in the same direction as the other items
3. Items $73,82,85,91$ and 93 were rescaled to measure in the same direction as the other items
4. Items $47,53,59,64$ and 69 were rescaled to measure in the same direction as the other items


Due to the relatively small sample size, the large number of items in the questionnaires, and the fact that the construct validity of the MMQ and SOC had been investigated previously in South African contexts, it was decided that the factor loadings when a single factor is extracted for each of the subscales as well as the inter-correlations between the sub-scales, would suffice for convergent and discriminant validity evidence in the present study. A separate principal axis factor analysis extracting a single factor per sub-scale was therefore performed on the items of each of the subscales. High loadings on the factor for the items of a sub-scale, was regarded as confirmation that the items were measuring the same construct. The factor loadings were also used to establish whether the items that the questionnaire developers had indicated as being negatively worded, indeed had to be reverse scored. If none of the items were to yield very low factor loadings, the computation of the Cronbach alpha reliabilities would be the appropriate next step.

In Table 2 the single factor loadings and Cronbach alpha internal consistency reliabilities of the MMQ sub-scales are given and in Table 3 the inter-correlations between the subscales are presented. In the case of seven items only were the factor loadings smaller than 0,30 . Inspection of Table 3 showed that four of the MMQ sub-scales formed a cluster with high intercorrelations, namely Competitiveness, Assertiveness, Power motive and Desire for a distinctive group role. The correlations ranged between 0,38 and 0,62 . These sub-scales therefore measured a common factor. The sub-scales Attitude towards authority figures and Willingness to conduct administrative functions were not substantially correlated with any other subscale and one may therefore assume that these scales measured two distinct constructs.

TABLE 3

INTER-CORRELATIONS BETWEEN THE MANAGERIAL MOTIVATION SUB-SCALES $(\mathbf{N}=\mathbf{1 2 4})$

\begin{tabular}{|c|c|c|c|c|c|c|}
\hline & Attitude & $\begin{array}{c}\text { Competi- } \\
\text { tiveness }\end{array}$ & $\begin{array}{l}\text { Assertive- } \\
\text { ness }\end{array}$ & Power & Desire & Admin \\
\hline $\begin{array}{l}\text { Attitude towards } \\
\text { authority figures }\end{array}$ & $s \frac{1,00}{(0,0)}$ & & & & & \\
\hline $\begin{array}{l}\text { Competi- } \\
\text { tiveness }\end{array}$ & $\begin{array}{c}0,16 \\
(0,069)\end{array}$ & $\frac{1,00}{(0,0)}$ & & & & \\
\hline Assertiveness & $\begin{array}{c}-0,14 \\
(0,101)\end{array}$ & $\underline{0,38}$ & $\frac{1,00}{(0,0)}$ & & & \\
\hline Power motive & $\begin{array}{c}0,10 \\
(0,250)\end{array}$ & $\frac{0,60}{(0,000)}$ & $\frac{0,62}{(0,000)}$ & $\frac{1,00}{(0,0)}$ & & \\
\hline $\begin{array}{l}\text { Desire for a } \\
\text { distinctive } \\
\text { group role }\end{array}$ & $\begin{array}{c}0,01 \\
(0,848)\end{array}$ & $\underline{0,51}$ & $\frac{0,40}{(0,000)}$ & $\begin{array}{c}0,43 \\
(0,000)\end{array}$ & $\frac{1,00}{(0,0)}$ & \\
\hline $\begin{array}{l}\text { Willingness to } \\
\text { conduct admin } \\
\text { functions }\end{array}$ & $\begin{array}{c}0,29 \\
(0,001)\end{array}$ & $\begin{array}{c}0,2 \\
(0,001)\end{array}$ & $\begin{array}{c}0,26 \\
(0,002)\end{array}$ & $\begin{array}{c}0,32 \\
(0,000)\end{array}$ & $\begin{array}{c}0,05 \\
(0,509)\end{array}$ & $\frac{1,00}{(0,0)}$ \\
\hline
\end{tabular}

$\mathrm{p}$ values are given in parentheses

Correlations larger than 0,35 are given in bold

From Table 2 it is clear that the items that were reverse coded were the ones indicated by the test developers as being negatively worded. Only $7 \%$ of the items had factor loadings smaller than 0,30 . In view of the satisfactory alpha coefficients obtained (varying from 0,76 to 0,85 ), it was decided not to tamper with the original questionnaire by omitting some items from the sub-scales for the purposes of the present study.

In Table 4 the single factor loadings and Cronbach alpha internal consistency reliabilities of the SOC sub-scales are given and in Table 5 the inter-correlations between the subscales are presented. Only Item 3 yielded a factor loading of less than 0,30 on its particular sub-scale and one may therefore assume that the items were adequate measures of the constructs that they were supposed to represent. The pattern of inter-correlations in Table 5 shows that the three subscales of the SOC are highly interrelated. The correlations ranged between 0,56 and 0,70 . This indicates that the SOC sub-scales may be combined to provide an indication of overall sense of coherence.

\section{TABLE 4}

SiNGLE FACTOR LOADINGS AND CRONBACH ALPHAS FOR THE SOC SUBSCALES

\begin{tabular}{lccccc}
\hline \multicolumn{2}{c}{ Comprehension } & \multicolumn{2}{c}{ Manageability } & \multicolumn{2}{c}{ Meaningfulness } \\
\hline Item & Factor loading & Item & Factor loading & Item & Factor loading \\
\hline 1 & $-0,46$ & 2 & $-0,53$ & 4 & 0,39 \\
3 & $\underline{0,21}$ & 6 & 0,65 & 7 & 0,63 \\
5 & $-0,45$ & 9 & $-0,46$ & 8 & $-0,76$ \\
10 & 0,37 & 13 & 0,73 & 11 & 0,66 \\
12 & 0,69 & 18 & $-0,45$ & 14 & 0,79 \\
15 & 0,50 & 20 & $-0,62$ & 16 & 0,66 \\
17 & 0,32 & 23 & 0,71 & 22 & $-0,75$ \\
19 & 0,72 & 25 & 0,58 & 28 & $-0,74$ \\
21 & 0,74 & 27 & 0,65 & & \\
24 & 0,75 & 29 & $-0,66$ & & \\
26 & 0,49 & & & & \\
\hline
\end{tabular}

Alpha $=0,751 \quad$ Alpha $=0,802$
Factor loadings smaller than 0,30 are printed in bold
1. Items 1 and 5 were rescaled to measure in the same direction as the other items
2. Items $6,13,20,23,25$ and 27 were rescaled to measure in the same direction as the
other items
3. Items $4,7,11,14$ and 16 were rescaled to measure in the same direction as the other
items

TABLE 5

INTER-CORRELATIONS BETWEEN THE SENSE OF COHERENCE SUB-SCALES $(\mathrm{N}=124)$

\begin{tabular}{|c|c|c|c|c|}
\hline & $\begin{array}{l}\text { Compre- } \\
\text { hension }\end{array}$ & $\begin{array}{c}\text { Manage- } \\
\text { ability }\end{array}$ & $\begin{array}{l}\text { Meaning- } \\
\text { fulness }\end{array}$ & SOC total \\
\hline Comprehension & $\frac{1,00}{(0,0)}$ & & & \\
\hline Manageability & $\frac{0,65}{(0,000)}$ & $\frac{1,00}{(0,000)}$ & & \\
\hline Meaningfulness & $\frac{0,56}{(0,000)}$ & $\frac{\underline{0,70}}{(0,000)}$ & $\frac{1,00}{(0,000)}$ & \\
\hline SOC total & $\frac{\underline{0,86}}{(0,000)}$ & $\frac{\underline{0,90}}{(0,000)}$ & $\underline{0,84}$ & $\frac{1,00}{(0,0)}$ \\
\hline
\end{tabular}

$\mathrm{p}$ values are given in parentheses

Correlations larger than 0,35 are given in bold

As was the case with the MMQ, the items that were reverse coded were the ones indicated by the test developers as being negatively worded (see Table 4). Furthermore, only one of the items had a factor loading smaller than 0,30 . This pattern of results together with the satisfactory alpha coefficients obtained (varying from 0,75 to 0,81 ), led to the decision to use the original questionnaire unaltered.

To obtain an answer to the first aim of the study, namely to assess whether there are statistically significant positive relationships between the sub-dimensions of sense of coherence and managerial motivation, the Pearson correlations between the sub-scales of the MMQ and SOC (including SOC total) were computed. The results are presented in Table 6 .

In Table 6 it is seen that none of the SOC sub-scales or SOC Total correlate statistically significantly with the MMQ's Attitude towards authority figures. In contrast, the SOC sub- 
scales and SOC Total correlate statistically significantly with all of the remaining MMQ sub-scales at the 0,01 significance level. There is one exception, namely a non-significant correlation of $\mathrm{r}=0,22(\mathrm{p}=0,012)$ between Meaningfulness (SOC) and Willingness to conduct administrative functions (MMQ).

TABLE 6

CORRELATIONS BETWEEN MANAGERIAL MOTIVATION AND SENSE OF COHERENCE SUB-SCALES

\begin{tabular}{|c|c|c|c|c|}
\hline \multirow{2}{*}{$\begin{array}{l}\text { Managerial motivation } \\
\text { sub-scales }\end{array}$} & \multicolumn{4}{|c|}{ Sense of coherence subscales } \\
\hline & $\begin{array}{l}\text { Compre- } \\
\text { hension }\end{array}$ & $\begin{array}{l}\text { Manage- } \\
\text { ability }\end{array}$ & $\begin{array}{l}\text { Meaning- } \\
\text { fulness }\end{array}$ & $\begin{array}{l}\text { SOC } \\
\text { total }\end{array}$ \\
\hline $\begin{array}{l}\text { Attitude towards authority } \\
\text { figures }\end{array}$ & $\begin{array}{c}0,18 \\
(0,034)\end{array}$ & $\begin{array}{c}0,13 \\
(0,129)\end{array}$ & $\begin{array}{c}-0,02 \\
(0,769)\end{array}$ & $\begin{array}{c}0,12 \\
(0,160)\end{array}$ \\
\hline Competitiveness & $\underline{0,24}$ & $\underline{0,27}$ & $\underline{0,30}$ & $\frac{0,31}{(0,000)}$ \\
\hline Assertiveness & $\underline{0,36}$ & $\underline{0,44}$ & $\underline{0,36}$ & $\underline{0,44}$ \\
\hline Power motive & $\underline{0,38}$ & $\underline{0,43}$ & $\frac{0,41}{(0,000)}$ & $\underline{0,47}$ \\
\hline $\begin{array}{l}\text { Desire for a distinctive } \\
\text { group role }\end{array}$ & $\underline{0,31}$ & $\underline{0,31}$ & $\begin{array}{c}0,22 \\
(0,012)\end{array}$ & $\frac{0,32}{(0,000)}$ \\
\hline $\begin{array}{l}\text { Willingness to conduct } \\
\text { admin functions }\end{array}$ & $\frac{0,32}{(0,000)}$ & $\underline{0,23}$ & $\frac{0,28}{(0,001)}$ & $\frac{0,32}{(0,000)}$ \\
\hline
\end{tabular}

$\mathrm{p}$ values are given in parentheses

Statistically significant correlations at $\alpha=0,01$ are given in bold

The second aim of the study was to establish whether there were statistically significant differences between managers and supervisors on the sub-dimensions of the sense of coherence and managerial motivation constructs. A series of nondirectional $t$ tests for independent groups were conducted on the means of managers and supervisors on the questionnaire variables. In Table 7 the means, standard deviations, and $p$ values related to these comparisons are provided. Using 0,05 as the significance level, only two comparisons were statistically significant. With regard to SOC Meaningfulness and MMQ Power motive, the managers obtained significantly higher mean scores than the supervisors $(\mathrm{p}=0,018$ and $\mathrm{p}<0,0001$ respectively).

TABLE 7

MEAN SCORES AND T TESTS ON THE MMQ AND SOC SCALES FOR MANAGERS AND SUPERVISORS

\begin{tabular}{llccccc}
\hline & Dimensions & \multicolumn{2}{c}{$\begin{array}{c}\text { Managers } \\
(\mathbf{N}=\mathbf{5 1})\end{array}$} & \multicolumn{2}{c}{$\begin{array}{c}\text { Supervisors } \\
(\mathbf{N}=\mathbf{7 3})\end{array}$} & $\mathrm{p}$ \\
\hline & & $\mathrm{M}$ & $\mathrm{SD}$ & $\mathrm{M}$ & $\mathrm{SD}$ & \\
\hline Sense of & Comprehension & 61,14 & 13,85 & 60,08 & 12,91 & 0,661 \\
Coherence & Manageability & 72,93 & 11,83 & 69,17 & 14,97 & 0,137 \\
& Meaningfulness & 81,09 & 10,04 & 75,16 & 15,46 & 0,018 \\
& SOC total & 70,75 & 10,35 & 67,37 & 12,71 & 0,118 \\
Managerial & Attitude towards & 62,83 & 12,99 & 64,67 & 15,37 & 0,485 \\
Motivation & authority figures & & & & & \\
& Competitiveness & 68,37 & 12,63 & 65,87 & 12,04 & 0,267 \\
& Assertiveness & 66,03 & 12,43 & 62,10 & 14,33 & 0,115 \\
& Power motive & 74,95 & 11,21 & 67,61 & 11,84 & 0,000 \\
& Desire distinctive & 46,65 & 17,64 & 46,07 & 18,51 & 0,861 \\
& role & & & & & \\
& Willingness admin & 70,90 & 15,91 & 68,46 & 16,24 & 0,407 \\
\hline
\end{tabular}

$\mathrm{p}$-values for non-directional $\mathrm{t}$ tests for independent samples are provided

\section{DISCUSSION}

Before attention was paid to investigating the principal aims of the study, the psychometric properties of the two measuring instruments used in the present study, namely the MMQ and the SOC, were assessed. In terms of reliability, all of the obtained Cronbach alpha coefficients were of a satisfactory magnitude. These results supported the findings obtained by Engelbrecht (1991) for the MMQ and those by Antonovsky (1993) and Frenz et al. (1993) for the SOC. In South Africa, Danana (1989), Strümpfer and Wissing (1998) and Du Toit, Coetzee and Visser (2005) also reported satisfactory internal consistency reliabilities for the SOC.

The construct validity of the sub-scales of the MMQ and SOC were investigated by examining the factor loadings when a single factor was extracted for each of the sub-scales as well as by examining the inter-correlations between the sub-scales. Generally, high factor loadings were obtained for the items and it was therefore concluded that the items of each sub-scale contributed towards measuring the construct in question. An interesting pattern of intercorrelations for the MMQ emerged when the correlations were studied for evidence of convergent and discriminant validity. Similar results have not been reported on in earlier studies. The results suggest that the MMQ measures three distinct factors, namely Attitude towards authority figures, Willingness to conduct administrative functions and a cluster consisting of four subscales (Competitiveness, Assertiveness, Power motive and Desire for a distinctive group role). Keeping in mind the content nature of the latter four scales, it makes logical sense that they should be correlated.

With regard to the SOC, the three sub-scales were highly interrelated, indicating that sense of coherence may be regarded as a single-dimensional construct. The inter-correlations ranged from 0,56 and 0,70 . These findings are in line with those obtained by earlier researchers. Antonovsky $(1979,1987)$ was unable to find empirical verification of the three-factor structure of sense of coherence. Similarly, Frenz et al. (1993) obtained intercorrelations of 0,71 or higher between the subscales. In a South African study, Breed, Cilliers and Visser (2005) obtained two viable factor solutions, namely a one-factor solution and a two-factor solution. The two-factor solution yielded factors that were labelled as Meaningfulness and Comprehensibility. The items of the original Manageability sub-scale loaded on either of the two factors. Overall, it was concluded that the MMQ and SOC met the psychometric requirements needed for the present study.

The first aim of the study, namely to assess whether there were statistically significant positive relationships between the subdimensions of sense of coherence and managerial motivation yielded mixed results. None of the sense of coherence scales correlated with Attitude towards authority figures (MMQ). Also, Meaningfulness (SOC) and Willingness to conduct administrative functions (MMQ) did not correlate. However, the remainder of the correlations, which represented the majority, supported the research hypothesis, because they were positive and statistically significant. It is concluded that there is a strong positive relationship between managerial motivation and sense of coherence.

When interpreting the lack of correlation between sense of coherence and Attitude towards authority figures (MMQ) a possible explanation may be that the dimensions of sense of coherence represent the psychologically strong part of an individual, whereas Attitude towards authority figures refers to the ready acceptance of authority imposed by authority figures. This does not imply that persons with a strong sense of coherence would not accept authority, 
but rather that such persons would prefer to be in a position of authority themselves.

The second objective of the study was to establish whether managers and supervisors differed with regard to sense of coherence and managerial motivation. Statistically significant differences were obtained for only two variables, namely Meaningfulness (SOC) and Power motive (MMQ). Apart from these two exceptions, the hypothesis that managers and supervisors would show differences regarding sense of coherence and managerial motivation dimensions could not be substantiated.

Antonovsky (1979) referred to the aspect of meaningfulness as stimuli impinged on a person being experienced as meaningful. In particular, it refers to the extent to which one feels that life makes sense emotionally. Importantly, Antonovsky (1987) mentioned that the motivational component of meaningfulness is crucial, because without it high comprehensibility or manageability scores are likely to be temporary.

The group of managers might have obtained significantly higher meaningfulness scores than the supervisors as a result of external variables. An aspect that might have contributed to this difference is the type of work performed by the two groups. Whereas it would be safe to argue that the majority of the persons in both groups were busy with activities that involved research on a daily basis, this does not mean that the tasks of managers and supervisors were similar. The managers were mainly responsible for the development of research protocols, whereas the supervisors were responsible for executing the work according to the protocols developed by the managers. The execution of this work according to the protocol involved the supervision of lower-level workers.

Since managers were mainly responsible for proposing and planning projects and therefore experienced sets of stimuli that made sense to them (because they had developed the protocols), they might have experience enhanced feelings of meaningfulness (in comparison with supervisors). Because supervisors mainly executed proposals that had been developed by managers, they might find stimuli less meaningful. This variance has not been explained in the literature previously and therefore requires more research.

With regard to the differences found for the Power motive (MMQ), the difference in the type of work performed by managers and supervisors may once more offer an explanation. According to Miner (1978) and Miner, Ebrahimi and Wachtel (1995), managers must exercise power over subordinates and direct their behaviour. They must tell others what to do and enforce their words through appropriate use of positive and negative sanctions. Individuals who find such behaviour difficult and emotionally disturbing, who do not wish to impose their wishes on others, or who believe it is wrong to do so, do not meet the role prescription of a manager. It was to be expected that managers would find it easier than supervisors to exercise power over subordinates and direct their behaviour.

Engelbrecht (1989) mentioned that males scored significantly higher than females with regard to the power motive and that the power motive correlated positively with job grade, experience of supervision, and number of subordinates, among others. The variance between managers and supervisors in terms of the power motive might thus be attributed to job grade, number of subordinates, years of experience, and the fact that there were more males in the managerial group than in the supervisory group.

To the extent that managerial motivation is one of the determinants of job performance (Ivancevich \& Matteson, 1996), it is evident that managerially motivated persons and persons with a strong sense of coherence should be appointed in managerial and supervisory positions, because the results of the present study indicated that sense of coherence and managerial motivation are strongly related.

\section{REFERENCES}

Antonovsky, A. (1979). Health, stress and coping. San Francisco: Jossey-Bass.

Antonovsky, A. (1984a). A call for a new question - Salutogenesis - and a proposed answer - the sense of coherence. Journal of Preventative Psychiatry, 2 (1), 1-13.

Antonovsky, A. (1984b). The Sense of Coherence as a Determinant of Health. In J.D. Matarazzo (Ed.), Behavioral health: A handbook of health enhancement and disease prevention. New York: John Wiley.

Antonovsky, A. (1987). Unravelling the mystery of health: How people manage stress and stay well. San Francisco: Jossey-Bass.

Antonovsky, A. (1991). The structural sources of salutogenic strengths. In C.L. Cooper \& R. Payne (Eds.), Personality and stress: Individual differences in the stress process (pp. 67-104). New York: John Wiley.

Antonovsky, A. (1993). The structure and properties of the sense of coherence scale. Social Science and Medicine, 36 (6), 725 733.

Breed, M., Cilliers, F. \& Visser, D. (2005). The factor structure of six salutogenic constructs. South African Journal of Industrial Psychology. In print.

Boyatzis, R.E. (1982). The competent manager. New York: Wiley.

Boyd, A. (1997). Employee traps - corruption in the workplace. Management Review, 86, 9.

Breakwater Monitor Report (July 1999). University of Cape Town.

Breakwater Monitor Report (Millenium Edition 2000). University of Cape Town.

Chamberlain, K. \& Zika, S. (1988). Measuring meaning in life: An examination of three scales. Personality and Individual Differences, 9 (3), 589-596.

Danna, K. \& Griffin, R.W. (1999). Health and well-being in the workplace: A review and synthesis of the literature. Journal of Management, 25 (3), 357-384.

Danana, D. (1989). Relationships between stressors and outcomes amongst nurses. Unpublished Report, Department of Psychology, University of Cape Town.

Deci, E.L. (1975). Intrinsic motivation. New York: Plenum.

Du Toit, F., Coetzee, S. \& Visser, D. (2005). The relation between personality type and sense of coherence among technical workers. Southern African Business Review, 9 (1), 51-65.

Employment Equity Act, No 55 (1998). Government Gazette, 400 (19370).

Engelbrecht, A.S. (1989). Die rol van bestuursmotivering in bestuurspotensiaal, bestuursdoeltreffendheid en bestuurstevredenheid. Unpublished doctoral thesis. University of Stellenbosch.

Engelbrecht, A.S. (1991). Die ontwikkeling van die Bestuursmotiveringsvraelys (BMV). Journal of Industrial Psychology, 17 (2), 7-13.

Engelbrecht, A.S. \& De Jager, L.C. (1991). Die betroubaarheid en faktorstruktuur van die aangepaste meervoudige keuseformaat van die Miner Sentence Completion Scale (MSCS). Journal of Industrial Psychology, 17 (2), 18-22.

Fineman, S. (1977). The achievement motive construct and its measurement: Where are we now? The British Journal of Psychology, 68, 1-22.

Flannery, R.B., Perry, J.B., Penk, W E. \& Flannery, G J. (1994). Validating Antonovsky's Sense of Coherence scale. Journal of Clinical Psychology, 50 (4), 575-577.

Frenz, A.W., Carey, M. \& Jorgensen, R.S. (1993). Psychometric evaluation of Antonovsky's Sense of Coherence Scale. Psychological Assessment, 5 (2), 145-153.

Global Competitiveness Report (1999). World Economic Forum.

Global Competitiveness Report (2000). World Economic Forum.

Ivancevich, J.M. \& Matteson, M.T. (1996). Organisational behaviour and management. Chicago: Irwin. 
Kohn, M.L. \& Schooler, C. (1982). Job conditions and personality: A longitudinal assessment of their reciprocal effects. American Sociological review, 87, 1257-1286.

Kohn, M.L. \& Schooler, C. (1983). Work and personality: An enquiry into the impact of social stratification. Norwood, NY: Ablex.

Kohn, M.L. \& Slomczynski, K.M. (1990). Social structure and selfdirection: A comparative analysis of the united States and Poland. Cambridge, MA: Blackwell.

McClelland, D.C. (1987). Human motivation. Cambridge: Cambridge University Press.

Miner, J.B. (1965). Studies in management education. New York: Springer.

Miner, J.B. (1978). Twenty years of research on role-motivation theory of managerial effectiveness. Personnel Psychology, 31, 739 - 760 .

Miner, J.B., Ebrahimi, B. \& Wachtel, J.M. (1995). How deficiencies in motivation to manage contribute to the United States' competitiveness problem (and what can be done about it). Human Resource Management, 34 (3), 363-387.

Miner, J.B. \& Smith, N.R. (1982). Decline and stabilisation of managerial motivation over a 20-year period. Journal of Applied Psychology, 67 (3), 297-305.

Miner, J.B., Smith, N.R. \& Bracker, J.S. (1989). Role of entrepreneurial task motivation on the growth of technologically innovative firms. Journal of Applied Psychology, 74 (4), 554-560.

Mintzberg, H. (1973). The manager's job: Folklore and fact. Harvard Business Review, 53, 49-61.

Montgomery, J.D. (1986). Levels of managerial leadership in Southern Africa. Journal of Developing Areas, 21, 15-30.

SAS User's Guide: Statistics, Version 5 Edition (1985) SAS Institute Inc., Cary, NC, USA.
Semmer, N. K. (2003). Individual differences, work stress and health. In M.J. Schabrach, J.A.M. Winnubst \& C.L. Cooper (Eds.), The handbook of work and health psychology (pp. 83108). New York: John Wiley.

Spangenberg, H. (1990). Assessing managerial competence. Kenwyn: Juta.

Spangenberg, J.J. \& Orpen-Lyall, M.R. (2000). Stress and coping strategies in a sample of South African managers involved in post-graduate managerial studies. Journal of Industrial Psychology, 26 (1), 6-10.

Strümpfer, D.J.W. (1990). Salutogenesis: A new paradigm. South African Journal of Psychology, 20 (4), 265-276.

Strümpfer, D. J. W. (1992). Psychological strengths as point of departure: Fortigenesis. Paper presented on occasion of receiving PASA award, annual congress, Psychological Association of South Africa, Stellenbosch.

Strümpfer, D. J. W. (1995). The origins of health: From 'salutogenesis 'to 'fortigenesis', South African Journal of Psychology, 25 (2), 81-89.

Strümpfer, D. J. W. (2003). Resilience and burnout: A stitch that could save nine. South African Journal of Psychology, 33 (2), 69-79.

Strümpfer, D. J. W. (2005). Standing on the shoulders of giants: Notes on early positive psychology (Psychofortology). South African Journal of Psychology, 35 (1) 21-45.

Strümpfer, D.J.W. \& Wissing, M. P. (1998, September). Review of South African data on the Sense of Coherence Scale as a measure of fortigenesis and salutogenesis. Paper presented at annual congress of the Psychological Society of South Africa, Cape Town.

Viviers, A.M. (1996). Salutogenese in organisatoriese konteks. Unpublished doctoral thesis. University of South Africa: Pretoria. 